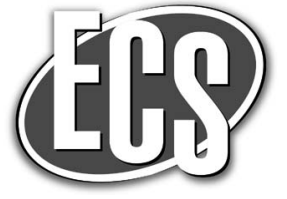

jSS Focus Issue on Printable Functional Materials for Electronics and Energy Applications

\title{
3D-Printing of Redox Flow Batteries for Energy Storage: A Rapid Prototype Laboratory Cell
}

\author{
L. F. Arenas, F. C. Walsh, ${ }^{, z}$ and C. Ponce de León \\ Electrochemical Engineering Laboratory, Energy Technology Research Group, Faculty of Engineering and the \\ Environment, University of Southampton, Southampton SO17 1BJ, United Kingdom
}

\begin{abstract}
Although interest in redox flow batteries (RFBs) for energy storage has grown over the last few years, implementation of RFB technology has been slow and challenging. Recent developments in 3D-printing of materials enable a transforming technology for fast, reproducible and documented cell manufacture. This technology can give an improved engineering approach to cell design and fabrication, needed to fulfil requirements for lower cost, longer lifetime hardware capable of efficient reliable performance. It can also be used to implement a flexible design methodology to suit various scales of operation, usually important during RFB development. In the case of electrolyte flow features, these needs are especially well met by fast prototyping strategies. This paper demonstrates the importance of 3D-printing for the realization of a hybrid zinc-cerium RFB laboratory cell. The design and fabrication process is described and the benefits offered by 3D-printing are considered. Finally, further opportunities offered by this approach to RFB manufacture and research are highlighted.

(C) The Author(s) 2015. Published by ECS. This is an open access article distributed under the terms of the Creative Commons Attribution Non-Commercial No Derivatives 4.0 License (CC BY-NC-ND, http://creativecommons.org/licenses/by-nc-nd/4.0/), which permits non-commercial reuse, distribution, and reproduction in any medium, provided the original work is not changed in any way and is properly cited. For permission for commercial reuse, please email: oa@electrochem.org. [DOI: 10.1149/2.0141504jss] All rights reserved.
\end{abstract}

Manuscript submitted December 2, 2014; revised manuscript received February 14, 2015. Published February 26, 2015. This paper is part of the JSS Focus Issue on Printable Functional Materials for Electronics and Energy Applications.

Growing solar and wind generation of electricity has increased the demand for energy storage capacity which is required to ensure adequate load levelling, stability and efficiency of the power grid. ${ }^{1}$ Redox flow batteries are important competitors in the energy storage industry for stationary applications. Currently, successful commercial systems include the all-vanadium ${ }^{2}$ and the zinc-bromine RFBs, ${ }^{3}$ while others are in the development phase. As illustrated in Figure 1, these devices are charged by using electricity to drive the redox reactions of chemical species dissolved in a flowing electrolyte solution in an electrochemical filter-press reactor. Energy is thus stored in the electrolytes, which are kept in external reservoirs. Electricity is released when charged electrolytes flow through the reactor and the electrode reactions take place in the reverse direction. Reviews detailing the principles and types of RFBs are available. ${ }^{1,4-7}$ Electrolyte, electrode and membrane choice has been investigated extensively and, as a result, engineering aspects of cell and stack design have acquired more importance.

In practice, all electrochemical reactors used in RFBs consist of stacks of filter-press type cells configuration. ${ }^{8}$ The main components include current collectors, bipolar electrodes, electrolyte flow frames, ion exchange membranes, and gaskets, which are carefully compressed in a pack between endplates. Flow channels are critical features of the cell bodies, since they direct the electrolyte flow to obtain uniform flow velocity and mass transport through the electrodes. Failure to achieve such conditions can result in localized reaction rates and lower efficiency, as well as problems with the heterogeneous deposition of metals when one of the redox couples is a metal subject to reduction (hybrid RFBs). Some of these components are common to other electrolysers and fuel cells.

Traditionally, components for filter-press reactors for RFBs have been manufactured by CNC (computer numerical control) machining, injection moulding and other common workshop and production techniques. Recently, 3D-printing has become an accessible and low cost alternative for the rapid production of cell prototypes as well as some of its components, in particular those having a high degree of complexity. Future developments are set to broaden the role of 3D-printing

*Electrochemical Society Active Member.

${ }^{\mathrm{z} E}$-mail: F.C.Walsh@ soton.ac.uk in RFB technology. This technique is also emerging in other fields of battery technology, particularly for integrated miniature primary ${ }^{9,10}$ and secondary ${ }^{11}$ static batteries.

\section{The Scope for 3D-Printing in Redox Flow Cells}

The importance of rapid prototyping and $3 D$-printing in $R F B$ technology. - The construction of RFB cells of different scales can benefit in several ways from 3D-printing techniques. Apart from its obvious application for industrial prototyping, these techniques can enable cost efficient and flexible design, which is critical during the early development of RFBs. In particular, electrolyte flow control at the electrodes and fluid sealing between adjacent cells in a stack can demand semi-continuous redesign of the polymeric frames of the reactor.

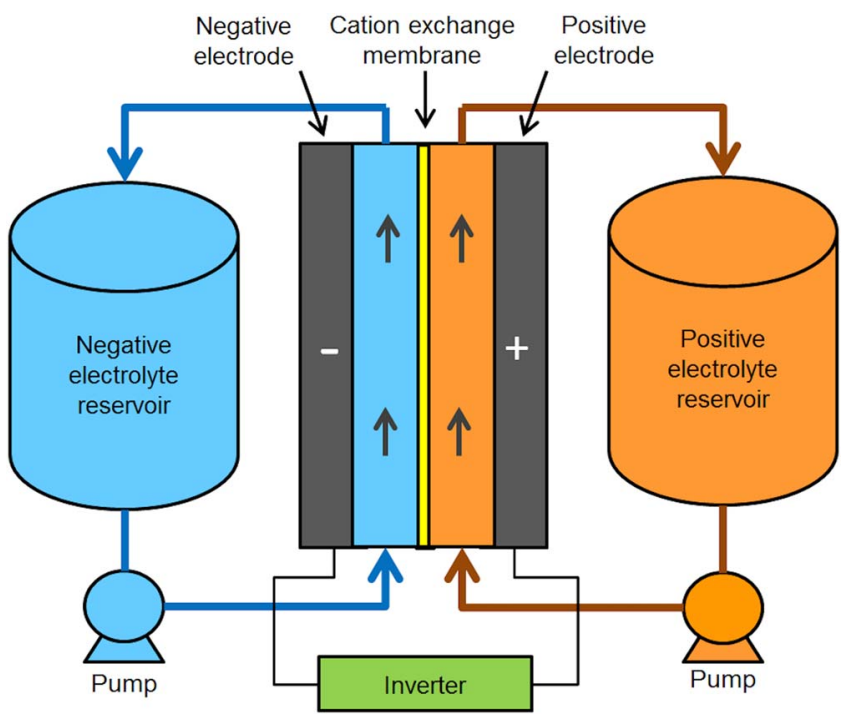

Figure 1. The principle of a classical redox flow battery system, showing a divided cell and electrolyte recirculation for each half-cell to a holding tank. 
Electrolyte flow through the electrode compartments determines the mass transport conditions and the current output of RFBs. Computational fluid dynamics (CFD) has become an important tool in the design of flow bodies for RFBs and other electrolysers. ${ }^{12} \mathrm{Nev}$ ertheless, many years of experience in electrochemical engineering research have shown that CFD models require validation against actual cells in order to produce meaningful and scalable results. ${ }^{13}$ Rapid prototyping can enable flow evaluation during process operation and its comparison against computational predictions.

A good example showing the convenience of 3D-printing in flow characterization studies is provided in recent work by Ponce de León et al., ${ }^{14}$ where the convective-diffusion limiting current for the reduction of ferricyanide ions at nickel electrodes was used to determine the mass transfer coefficient and the correlation between Sherwood and Reynolds numbers in a 3D-printed flow cell. Another example is provided by the work of $\mathrm{Bu}$ et al., ${ }^{15}$ in which printed matrices of inert spheres, having different tortuosity and pressure drop, were used to study flow transitions by monitoring the diffusion-determined limiting current at microelectrodes. A similar method could be used to optimize the mass transport produced by different flow patterns and turbulence promoters in flow batteries. The concept of 3D-printed flow channels has been used in electrodes for water electrolysis cells. ${ }^{16}$ Printed miniature fuel cells are also under development. ${ }^{17}$

Cost is an important driver for fast prototyping in RFB research and implementation. Flow frames and other components demand regular redesign at early development and pilot test stages, making the cost of injection moulding tooling prohibitive until the system has proved to be reliable. ${ }^{13}$ Computer numerical control (CNC) machining and cutting of polymer sheets has been used extensively, at the cost of imposing limitations on the complexity of flow features. Low-cost manufacture of complex components is normally impossible without mass production but $3 \mathrm{D}$-printing can also ease this time and marketing constraint. This is the case for labyrinthine pathway manifolds, ${ }^{18}$ which are used to avoid shunt or by-pass currents flowing via electrolyte manifolds among adjacent cells in a stack, decreasing efficiency. ${ }^{19,20}$ The combination of manufacturing techniques is an easily implemented alternative; for instance, an electrolyte flow frame can be fabricated via injection moulding with an 3D-printed sub-module acting as a distributor to control local flow. ${ }^{18}$

Rapid prototyping and 3D-printing in laboratory and small-scale RFBs. - Development of RFBs often starts in the laboratory, where single flow cells with electrode areas up to $100 \mathrm{~cm}^{2}$ are used to study the fundamental electrochemistry of the system, optimize electrolyte composition and select electrode materials before progressing to pilot plant operations. Rapid prototyping can aid in the design process of such cells and especially in the manufacture of critical components such as flow frames. 3D-printed laboratory scale flow cells might become a favored choice, since they permit fast, reliable manufacture at very low cost. This could be especially useful in the case of multi-cell reactors, seldom investigated at this scale in part due to the difficulties and expenses of their manufacture.

As in larger cells, the study of electrolyte flow uniformity delivered by different flow channel geometries can be easily studied by manufacturing and evaluating multiple prototypes at low cost. Additionally, click-in polymer inserts are one way of incorporating different internal flow distributors while retaining the same flow frame. This can also incorporate a mesh turbulence promoter between inlet port and inlet flow distributor, as exemplified by a cell used for a soluble lead acid flow battery. ${ }^{21}$

Required material properties. - An adequate choice of printable material is essential, as most electrolytes used in RFBs are corrosive acid-based solutions (sulfuric or methanesulfonic acid), sometimes containing strong oxidants in the positive electrolyte compartment. A long lifetime and reliability of RFBs is essential for their commercial implementation. At present, polyphenylsulfone offers a chemically resistant option for printed components, ${ }^{22}$ although research continues in this area. Thermal stability should not be a serious concern for most
RFB systems, as they often operate in the temperature range of 20 to $50^{\circ} \mathrm{C}$. Less chemically resistant materials, such as ABS (acrylonitrile butadiene styrene), can be used without major problems for short-term testing during development and with low acid concentrations.

\section{A Rapid Prototype Flow Cell for a Zn-Ce Flow Battery}

As part of our research on the zinc-cerium system, ${ }^{23}$ a new electrochemical flow reactor was designed to study the charge-discharge behavior, characterize the mass transport rate to the electrode surface and develop charge-discharge monitoring techniques. The zinccerium hybrid system delivers the highest thermodynamic open circuit voltage (ca. $+2.4 \mathrm{~V}$ ) of common RFBs. ${ }^{24}$ Zinc electrodeposition and dissolution takes place at the carbon-based negative electrode, while the anodic generation of $\mathrm{Ce}(\mathrm{IV})$ and its subsequent reduction requires a platinized titanium positive electrode. ${ }^{25}$ Both electrolytes use methanesulfonic acid (MSA) to achieve high concentration of the chemical species.

The fast-assembly cell consists of a rectangular channel filter-press flow reactor with the two symmetrical half-cells divided by a proton exchange membrane. The cell bodies or flow frames including internal flow fields, end plates and electrolyte compartments were manufactured by 3D-printing. Fastenings between the cell components were avoided in order to decrease the number of potential electrolyte leakage points. Cell components are aligned and held together in a rigid stainless steel case by means of mechanical compression applied by two $8 \mathrm{~mm}$ steel screws, as shown in Figure 2. This configuration helps to achieve minimum assembly time and minimum requirement of tools during the system set up. An expanded view of all the cell components is detailed in Figure 3.

Description of the cell and 3D-printing methods. - Low-cost cell components were obtained by 3D-printing, allowing immediate identification of problems and the creation of several versions of the cell,

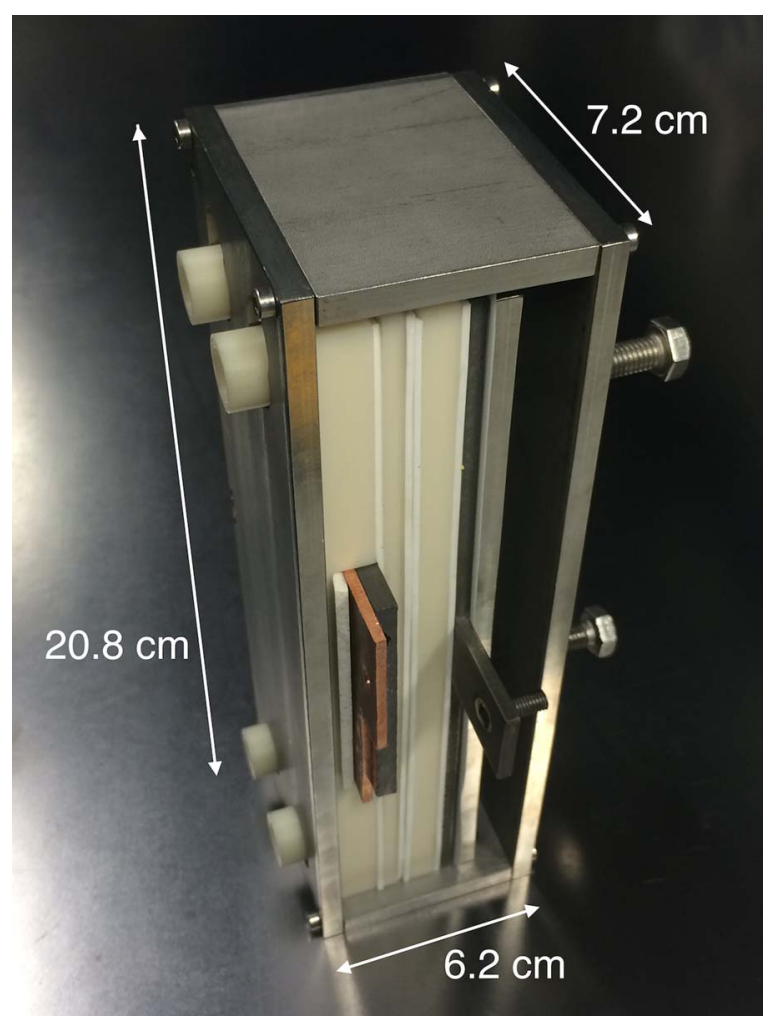

Figure 2. The constructed flow cell including 3D-printed electrolyte flow frames and endplate with electrolyte connections. A stainless steel case holds the components together in compression. 


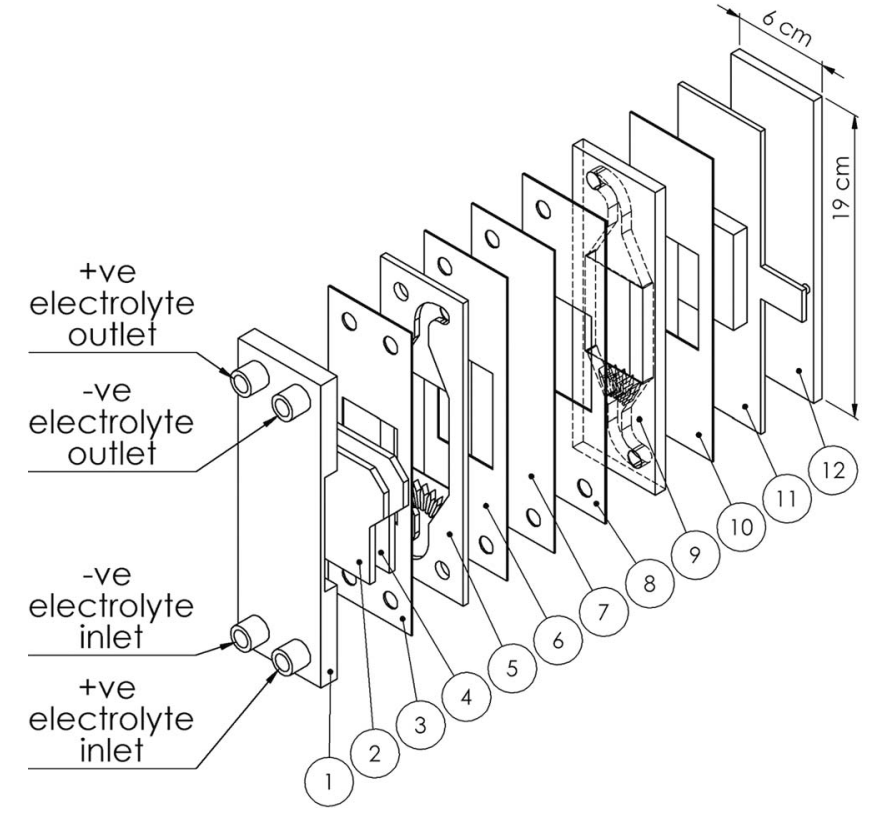

Figure 3. Expanded view of the components of a laboratory scale redox flow battery. 1) negative electrode endplate; 2) negative electrode copper current feeder; 3), 6), 8), 10) silicone rubber gaskets; 4) carbon-polymer composite negative electrode; 5) negative electrode flow frame; 7) proton exchange membrane; 9) positive electrode flow frame; 11) platinized titanium electrode and titanium current collector; 12) positive electrode endplate.

each of them accommodating new design improvements. CAD (computer assisted design) models for each part were created using Solidworks 2013 SP3.0 Education Edition (Dassault Systèmes SA). Cell bodies were manufactured in ABS using a Dimension 1200es printer (Stratasys Ltd.) with a layer thickness of $254 \mu \mathrm{m}$. The printing of the three bodies required approximately 8 hours. Surface roughness was measured with a Talysurf $120 \mathrm{~L}$ profilometer (Taylor Hobson Ltd). Electrolyte turbulence promoting meshes were also printed in ABS with the aid of an Up Plus 2 printer (Beijing Tier Time Technology Co. Ltd.), with a resolution of $200 \mu \mathrm{m}$ and a printing time of approximately 1.25 hours each.

The ABS 3D-printed flow frames, shown in Figure 4, include flow channels and have overall dimensions of $6 \mathrm{~cm} \times 19 \mathrm{~cm}$. The thickness of the flow frames is $0.4 \mathrm{~cm}$ and $1.0 \mathrm{~cm}$ for the negative and

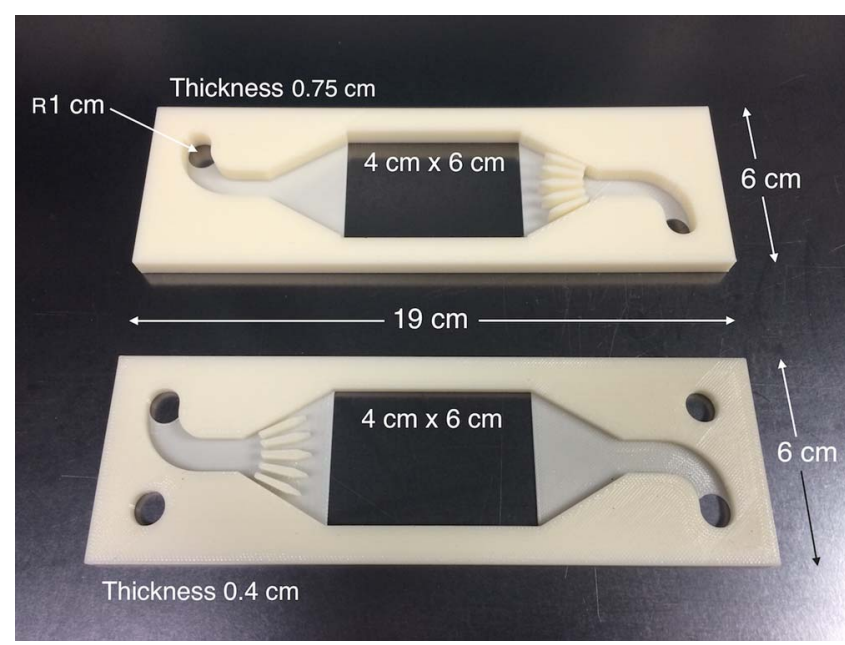

Figure 4. 3D-printed cell frames for an RFB including electrolyte flow channels for uniform electrolyte flow.

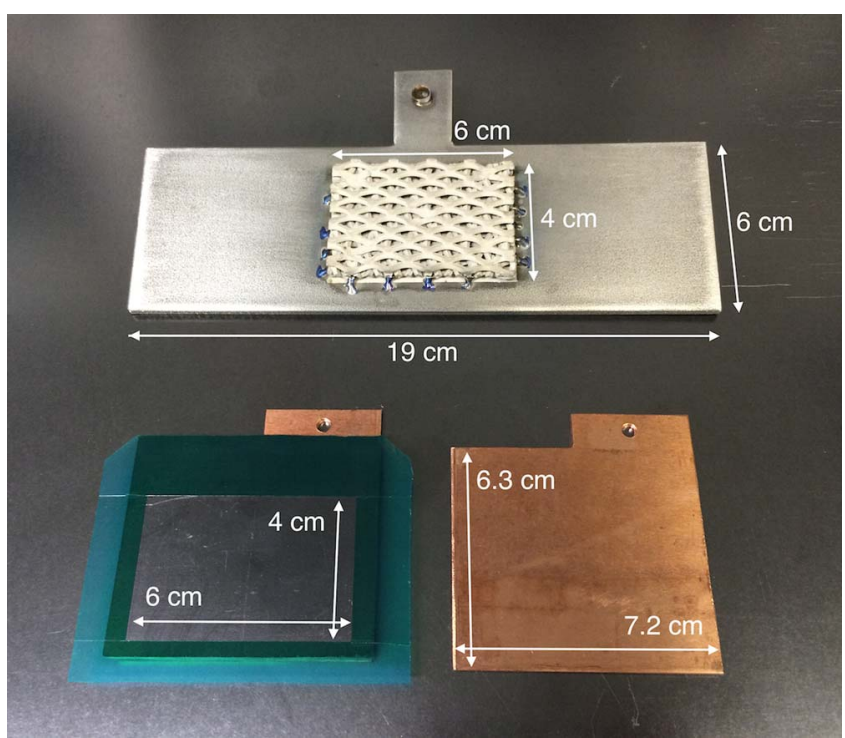

Figure 5. Platinized titanium electrode and titanium current collector, top; polymer based negative electrode delimited by insulating tape, bottom-left; copper negative current feeder, bottom-right.

positive half-cells, respectively (as each half-cell requires different electrode materials). Electrode compartments have a length of $6 \mathrm{~cm}$ and a breadth of $4 \mathrm{~cm}$ and $4.2 \mathrm{~cm}$ for the positive and negative halfcells, respectively. A Nafion 117 proton exchange membrane separates the two half-cells of the flow battery. Silicone rubber foam gaskets with $2 \mathrm{~mm}$ thickness (ca. $1 \mathrm{~mm}$ when compressed) and a density of $0.25 \mathrm{~g} \mathrm{~cm}^{-3}$ were used. The negative current collector is embedded in an insulating printed frame, which also includes the inlet and outlet manifolds for bottom to top electrolyte flow. A $0.5 \mathrm{~mm}$ thick polytetrafluoroethylene sheet electrically insulates the base and sides of the cell components from the stainless steel box. The compression case for the cell components was manufactured from $4 \mathrm{~mm}$ thick SAE 304 stainless steel.

The positive electrode of the cell (Magneto Special Anodes BV) consisted of three $2 \mathrm{~mm}$ thick titanium meshes (expanded, nonflattened) spot-welded together onto a titanium plate current collector/feeder and uniformly coated by a $3.5 \mu \mathrm{m}$ thick platinum electrodeposit. The platinum loading was approximately $7 \mathrm{mg} \mathrm{cm}^{-2}$. The dimensions of the positive electrode and the current feeder were 6.0 $\times 4.0 \times 1.0 \mathrm{~cm}$ (projected area of $24 \mathrm{~cm}^{2}$ ) and $19.0 \times 6.0 \times 0.4 \mathrm{~cm}$, respectively. A graphitized fluorocarbon polymer-composite, Sigracet BMA5 bipolar plate (SGL Carbon $\mathrm{GmbH}$ ) was used as the negative electrode. Its dimensions were $6.3 \times 7.2 \mathrm{~cm}$ and a thickness of 5 $\mathrm{mm}$ with an active area of $6.0 \times 4.0 \mathrm{~cm}$, delimited by polyester insulating tape and attached to a $2.3 \mathrm{~mm}$ thick copper plate current collector/feeder. The electrodes and current feeders are presented in Figure 5.

A design brief in Table I documents the cell design, presenting some of the dimensions and hydraulic characteristics of the two halfcells of the flow battery for the planed operating conditions, including mean linear electrolyte flow rates between 1 and $10 \mathrm{~cm} \mathrm{~s}^{-1}$. The relationship between mean linear flow velocity, $v$ and volumetric flow rate, $Q_{v}$ though a rectangular channel of cross-sectional area, $A_{x}$ (the product of breadth, $B$ and height, $S$ of the channel) is given by:

$$
v=\frac{Q_{v}}{B S}=\frac{Q_{v}}{A_{x}}
$$

Several dimensions of the cell are needed for the calculation of Reynolds and Sherwood numbers for flow characterization at the electrode compartments. ${ }^{8}$ These include the equivalent (hydraulic) 
Table I. The design brief for a laboratory scale RFB.

\section{Parameter}

Projected geometrical area of each electrode

Minimum interelectrode gap

Length of electrodes in the direction of flow

Breadth of -ve half-cell flow channel

Breadth of + ve half-cell flow channel

Height of -ve half-cell flow channel (including gaskets)

Height of + ve half-cell flow channel (including gaskets)

Cross section area of -ve half-cell flow channel

Cross section area of + ve half-cell flow channel

Aspect ratio of -ve half-cell flow channel

Aspect ratio of + ve half-cell flow channel

Hydraulic diameter of -ve half-cell flow channel

Hydraulic diameter of + ve half-cell flow channel

Dimensionless length group of -ve half-cell channel

Dimensionless length group of + ve half-cell channel

Mean linear flow velocity of electrolyte

Volumetric flow rate in -ve half-cell channel

Volumetric flow rate in + ve half-cell channel

Expected pressure drop over flow channels, $\Delta P$

Speed of assembly and opening

Typical negative half-cell electrolyte

Typical positive half-cell electrolyte

Electrolyte temperatures

diameter, $d_{e}$ :

$$
d_{e}=\frac{2 A_{x}}{B+S}
$$

dimensionless length group, $L e$ :

$$
L e=\frac{d_{e}}{L}
$$

where $L$ is the length of the electrodes, and the aspect ratio of the channel, $\gamma$ :

$$
\gamma=\frac{S}{B}
$$

In order to characterize the channels of this iteration of the cell design, the pressure at the inlet and outlet of each half-cell was measured with a Digitron 2028P manometer (Sifam Intruments Ltd). The pressure drop over a flow channel directly affects pumping power and overall energy efficiency. ${ }^{26}$ Volumetric flow rates using distilled water were set to achieve symmetrical linear flow velocities in both electrode compartments, in the range of 1 to $7 \mathrm{~cm} \mathrm{~s}^{-1}$ at $22^{\circ} \mathrm{C}$. Triplicate measurements were made at each flow rate and the average value used in the plot.

Discussion. - The ABS flow frames obtained by 3D-printing and shown in Figure 4 met a tolerance of $\pm 0.1 \mathrm{~mm}$ on overall dimensions. This precision is especially important in the case of flow features included in the inlet manifold of both flow frames, which would have been problematic to manufacture by traditional methods. Owing to the choice of a relatively high-quality $3 \mathrm{D}$-printer, the components were free from deformation caused by heat residual stress, a problem observed in previous work. ${ }^{14}$

The high density of the printed polymer $\left(0.93 \mathrm{~g} \mathrm{~cm}^{-3}\right)$ and the complete fusion of adjacent extruded filaments provided a non-porous structure impermeable to liquid electrolyte. The internal horizontal surface of the flow channels had an average surface roughness of $10.3 \pm 1.7 \mu \mathrm{m}$ in the direction of the electrolyte flow. The mechanical pressure applied by the stainless steel case was sufficient to keep components sealed with the aid of compressible silicone rubber gaskets. The use of an external case for this cell also facilitated its assembly.

\section{Symbol}

Value

$24.0 \mathrm{~cm}^{2}$

$0.7 \mathrm{~cm}$

$6.0 \mathrm{~cm}$

$4.0 \mathrm{~cm}$

$4.2 \mathrm{~cm}$

$0.6 \mathrm{~cm}$

$0.95 \mathrm{~cm}$

$2.4 \mathrm{~cm}^{2}$

$4.0 \mathrm{~cm}^{2}$

0.15

0.23

$1.043 \mathrm{~cm}$

$1.549 \mathrm{~cm}$

0.174

0.258

$1-10 \mathrm{~cm} \mathrm{~s}^{-1}$

$2.4-24 \mathrm{~cm}^{3} \mathrm{~s}^{-1}=8.6-86.4 \mathrm{dm}^{3} \mathrm{~h}^{-1}$

$4.0-40 \mathrm{~cm}^{3} \mathrm{~s}^{-1}=14.4-144.0 \mathrm{dm}^{3} \mathrm{~h}^{-1}$

$<1$ atm

$<2$ minutes

$1.5 \mathrm{~mol} \mathrm{dm}^{3} \mathrm{Zn}$ (II) methanesulfonate in $1.0 \mathrm{~mol} \mathrm{dm} \mathrm{dm}^{3}$ MSA

$0.8 \mathrm{~mol} \mathrm{dm}^{3} \mathrm{Ce}$ (III) methanesulfonate in $4.0 \mathrm{~mol} \mathrm{dm}^{3}$ MSA

$20-60^{\circ} \mathrm{C}$

Figure 6 shows that the pressure drop over the cell changes logarithmically with the flow velocity and the experimental data can be fitted into a power relationship of the type: $\Delta P=\mathrm{a} R e^{\mathrm{b}}$ which is showing in the figure for each compartment and compared with the relationship obtained for the FM01-LC reactor. ${ }^{26}$ The pressure drop measurements also revealed an important asymmetry between the two half-cells. The positive compartment presents a maximum pressure drop of $11 \mathrm{kPa}$ when the Reynolds number is about $1100\left(7 \mathrm{~cm} \mathrm{~s}^{-1}\right.$ mean linear flow rate), which is similar to the one observed in the FM01-LC cell. However, the pressure drop in the negative compartment reached values of $94 \mathrm{kPa}$ at the same linear flow velocity, indicating that geometrical

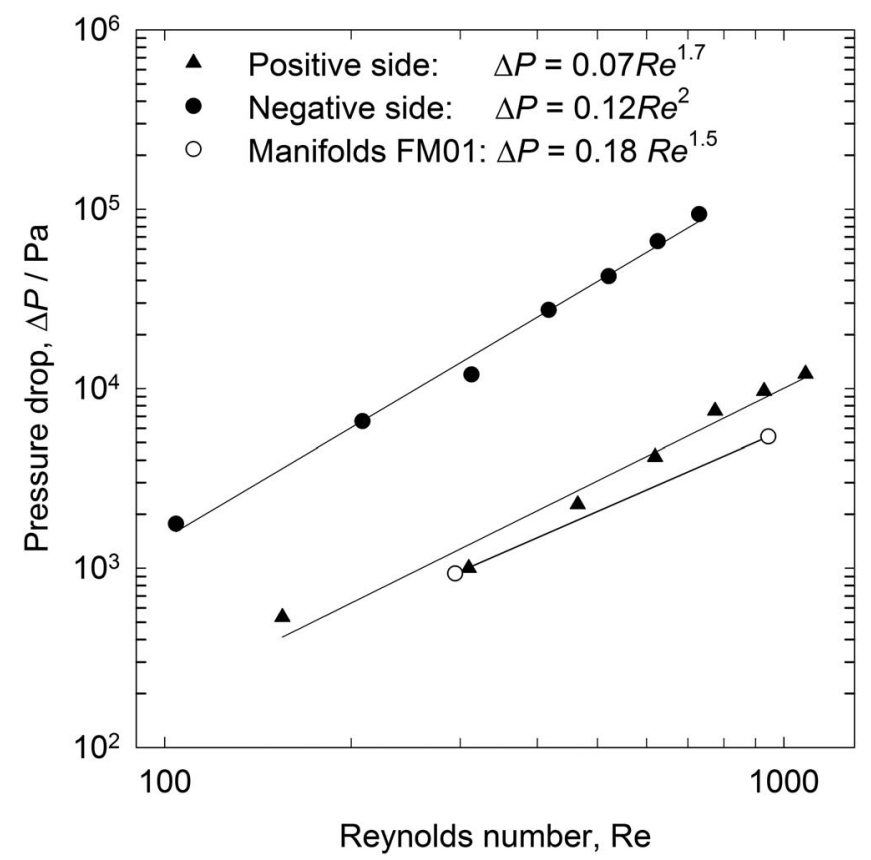

Figure 6. Pressure drop through the half-cells of the 3D-printed laboratory cell vs. Reynolds number. Data fitted into the power relationship $\Delta P=\mathrm{a} R e^{\mathrm{b}}$ and compared with the relationship obtained for the FM01-LC reactor. ${ }^{26}$ 


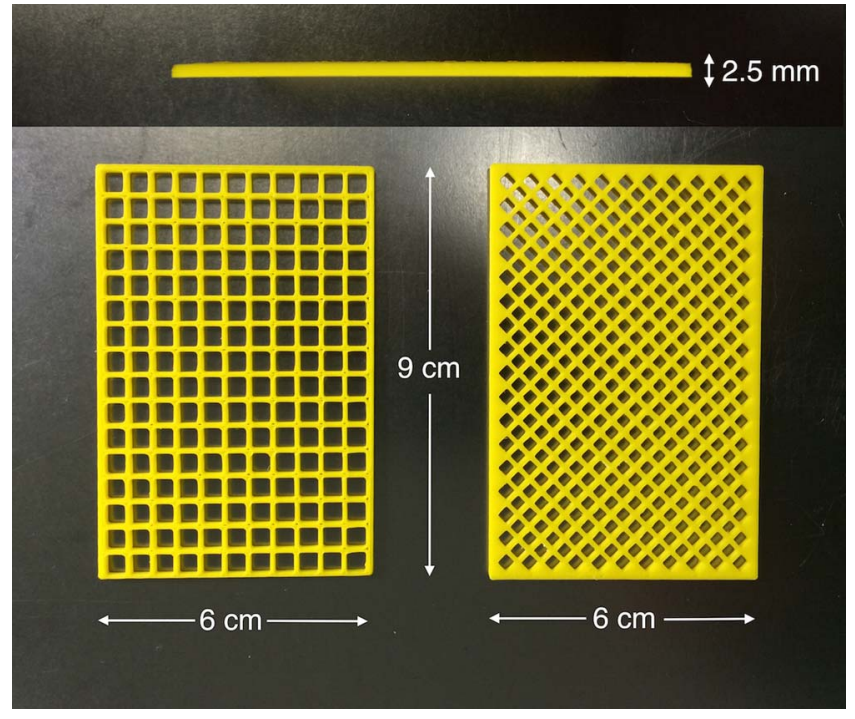

Figure 7. 3D-printed polymer turbulence promoters for use in flow batteries and other filter press electrochemical reactors. The square apertures have internal dimensions of $4.5 \times 4.5 \mathrm{~cm}$ and $3.1 \times 3.2 \mathrm{~cm}$ in the left and right hand side grids, respectively.

modifications are required in this component to reduce pressure drop. Printing a modified version of the cell can help to rapidly evaluate the performance of a new design.

Printed mesh-like turbulence promoters with diamond and square aperture shapes are shown in Figure 7. The cross-section view also shows the obtained flat profile. The printing resolution and software control of the printer used for these components was found to be important, as it was difficult to obtain material thin enough to form the separation between each internal square.

\section{Research Opportunities for 3D-Printing in RFB Technology}

Study of flow and mass transport near manifolds and in flow channels. - As previously mentioned, geometry and dimensions of the electrolyte manifolds and flow channels/distributors play a major role in obtaining uniform disperse flow at the electrodes. ${ }^{27}$ One of the challenges consists in controlling entrance and exit flow effects at inlet and outlet manifolds in individual cells. Shown in Figure 8, these features introduce the electrolyte into the electrode compartment, shaping the flow from circular to rectangular cross-section and dispersing jets. Common types of manifolds include tapered manifolds, tapered grooves and multiple internal holes. Frías-Ferrer et al. have described the effect of manifolds on electrolyte flow. ${ }^{27}$ 3D-printing offers a fast

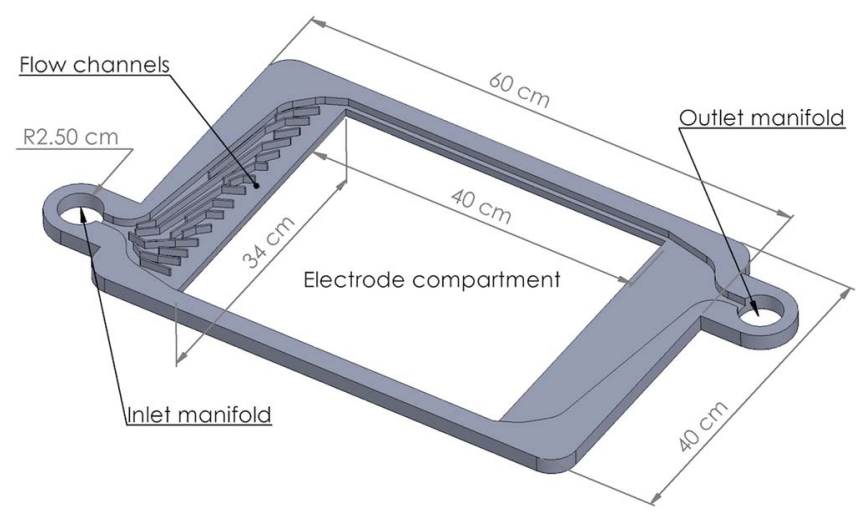

Figure 8. Electrolyte flow channels in the flow frame of an individual cell used in an industrial RFB. After Regenesys. ${ }^{18}$

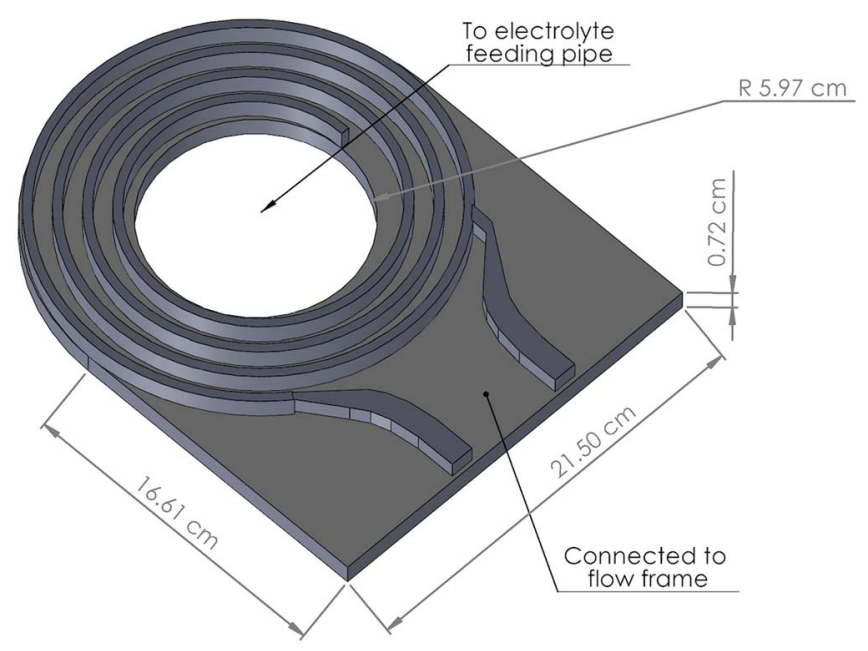

Figure 9. A section of a spiral path manifold used to prevent shunt currents though flowing electrolyte between adjacent cells in an industrial size RFB. After Regenesys. ${ }^{18}$

and flexible way to produce new design features for their evaluation in operating RFBs, thus facilitating the validation of fluid flow models. These flow distribution patterns can be printed as easily replaceable inserts, ${ }^{18}$ enabling the same flow frame to be used for multiple experiments.

3D-printing can also help to produce and evaluate spiral and other labyrinthine pathway manifolds, usually difficult and expensive to manufacture for development purposes. This type of manifold, ${ }^{18}$ illustrated in Figure 9, is used to increase the resistance across the electrolyte by extending its length; an alternative to long external polymer tubing. High-resistance electrolyte paths decrease the shunt or by-pass currents commonly found in stacks of individual electrochemical cells. ${ }^{19,20}$ Fast and low-cost printing can ease the study of fluid flow, pressure drop and electrolyte resistance conditions in these components.

Turbulence promoters and their effect on mass transport.- Increased mass transport in filter-press reactors, including RFBs with flow-by electrodes, can be accomplished by placing turbulence promoters within the electrolyte compartment. Commercial inexpensive polymer meshes that produce complicated hydrodynamic flow patterns in the electrolyte are used for this purpose. Up to now, the optimization of these meshes in terms of the correlation between their geometrical characteristics and the increase of mass transport has not being possible and is not fully understood. ${ }^{28}$ As shown by the examples in Figure 7, 3D-printing can enable easy manufacture of custom meshes with different shapes, dimensions, thicknesses and surfacearea ratios for their study. A mass transport enhancement factor can be used to compare turbulence promoter performance, as the studies by Ralph et al. have shown. ${ }^{28}$

Printed metallic and carbon-based electrodes. - Advances in 3Dprinting of metals and conductive polymers, as well as polymers coated with conductive materials, could lead to the manufacture of specialized high-surface area electrodes, a characteristic required for performance improvement of several RFBs. At present, macroscopic metallic electrodes such as nickel, iron, and titanium alloys can be printed by laser techniques. ${ }^{29}$ Printed high-surface area titanium structures are also available, ${ }^{30}$ and similar high-porosity titanium tissue scaffolds have been obtained by powder metallurgy, using 3D-printed wax templates. ${ }^{31}$ Such materials can be later platinized or coated with other catalytic or nanostructured materials in order to increase performance and provide chemical stability. Under the right conditions, 3D-printed electrodes with complex structures could also be designed as effective turbulence promoters. 
Bipolar carbon-based electrodes used in RFBs can also benefit from these manufacturing techniques. Graphite bipolar plates incorporating flow channels for methanol fuel cells have already demonstrated the feasibility of this concept by laser sintering of mixtures of graphite and phenolic powder. ${ }^{32}$ The incorporation of catalysts into printed electrodes could also add custom selectivity or/and increased reaction rates. ${ }^{33,34}$ Printed bipolar plates could also achieve non-conventional high-surface area profiles with interdigitated and reticular interfaces, ${ }^{35}$ useful to increase the area between electrodes separated by a flowing electrolyte. Direct deposition of printed carbon material onto metallic plates, could address one of the major problems in RFBs, i.e., the high electrical resistivity of the interface between metallic current feeders and carbon-based electrodes, which accounts for voltage and energy efficiency losses. ${ }^{36}$ Carbon-based electrodes with gradual transition from solid plate form into high-surface area material (felt or fibre) could also be used as a better alternative to electric contact by compression. The ultimate challenge must be the entire design and fabrication of an RFB cell stack integrating all cell components using a versatile 3D-printer able to print materials with different chemical and physical properties in a single operation.

\section{Conclusions}

The potential for 3D-printing manufacture of RFBs and other electrochemical flow reactors has been illustrated by the design and fabrication of a laboratory scale battery cell. 3D-printed flow frames and endplates met the requirements for experimental conditions while providing low-cost, design flexibility and rapid manufacture. The design of this cell included features that facilitated its fast assembly and reliability for repeated use in the laboratory. Custom flat turbulence promoters were also successfully printed, although more work is needed to obtain profiled turbulence promoters similar in profile to an expanded metal mesh. Flat, unprofiled turbulence promoters tend to block the electrode surface and provide less mass transport enhancement. ${ }^{28}$

\section{Future Outlook}

In combination with conventional manufacturing techniques, 3Dprinting should enable new developments in RFB technology, including new electrode materials and configurations, integrated components, miniaturized components, and convenient methods to study and optimize flow and mass transport in small and large cells. Fast prototyping 3D-printing can be used as an essential part of the design and fabrication process, especially for the optimization of electrolyte flow and mass transport in flow channels and flow manifold geometries along with the validation of computational flow and flow dispersion models.

\section{Acknowledgments}

L.F.A. acknowledges the financial support of the Mexican government through CONACYT and SEP overseas scholarships.

\section{References}

1. P. Alotto, M. Guarnieri, and F. Moro, Renew. Sust. Energ. Rev., 29(C), 325 (2014).

2. T. Shigematsu, SEI Technical Review, 73, 4 (2011).

3. Redflow Ltd. http://www.redflow.com; accessed 13 November 2014.

4. C. Ponce de León, A. Frías-Ferrer, J. González-García, D. A. Szánto, and F. C. Walsh, J. Power Sources, 160(1), 716 (2006).

5. A. Z. Weber, M. M. Mench, J. P. Meyers, P. N. Ross, J. T. Gostick, and Q. Liu, J. App. Electrochem., 41(10), 1137 (2011).

6. W. Wang, Q. Luo, B. Li, X. Wei, L. Li, and Z. Yang, Adv. Funct. Mater, 23(8), 970 (2012).

7. P. Leung, X. Li, C. Ponce de León, L. Berlouis, C. T. J. Low, and F. C. Walsh, RSC Advances, 2, 10125 (2012).

8. F. C. Walsh, A first course on electrochemical engineering, The Electrochemical Consultancy, Romsey (1993).

9. E. Malone, K. Rasa, D. Cohen, T. Isaacson, H. Lashley, and H. Lipson, Rapid Prototyping J., 10(1), 58 (2004)

10. E. Malone, M. Berry, and H. Lipson, Rapid Prototyping J., 14(3), 128 (2008)

11. K. Sun, T. S. Wei, B. K. Ahn, J. Y. Seo, S. H. Dillon, and J. A. Lewis, Adv. Mater. 25(33), 4539 (2013).

12. M. R. Cruz-Díaz, E. P. Rivero, F. J. Almazán-Ruiz, Á. Torres-Mendoza, and I. González, Chem. Eng. Process., 85, 145 (2014).

13. S. Clarke, Flow cells for energy storage workshop, Washington DC, US Department of Energy, Fuel Cells Technology Office (2012), http://energy.gov/eere/fuelcells/ flow-cells-energy-storage-workshop; last accessed 25 November 2014.

14. C. Ponce de León et al., Chem. Eng. Trans., 41, 1 (2014).

15. S. Bu, J. Yang, Q. Dong, and Q. Wang, Exp. Therm. Fluid Sci., 60, 106 (2015).

16. G. Chisholm, P. J. Kitson, N. D. Kirkaldy, L. G. Bloor, and L. Cronin, Energy Environ. Sci., 7, 3026 (2014).

17. F. J. del Campo, Electrochem. Commun., 45, 91 (2014).

18. D. C. Clark, S. H. Joseph, and H. S Oates, assigned to Regenesys Ltd., US Pat. 6524452 B1 (2003).

19. R. A. Scannell and F. C. Walsh, I. Chem. E. Symp. Ser., 112, 59 (1989).

20. K. Scott, W. Taama, and B.R. Williams, J. Appl. Electrochem., 28, 259 (1998).

21. J. Collins, G. Kear, X. Li, C. T. J. Low, D. Pletcher, R. Tangirala, C. Stratton-Campbell, F. C. Walsh, and C. Zhang, J. Power Sources, 195, 1731 (2010).

22. D. Bak, Assembly Autom., 23(4), 340 (2003)

23. F. C. Walsh, C. Ponce de Léon, L. Berlouis, G. Nikiforidis, L. F. Arenas-Martínez, D. Hodgson, and D. Hall, ChemPlusChem, 80, 288 (2015).

24. P. K. Leung, C. Ponce de León, C. T. J. Low, A. A. Shah, and F. C. Walsh, J. Power Sources, 196(11), 5174 (2011).

25. G. Nikiforidis, L. Berlouis, D. Hall, and D. Hodgson, Electrochim. Acta, 115, 621 (2014).

26. C. J. Brown, F. C. Walsh, and D. Pletcher, Trans. I. Chem. E., 73(A), 196 (1995).

27. A. Frías-Ferrer, J. González-García, V. Sáez, C. Ponce de León, and F. C. Walsh, AIChE Journal, 54(3), 811 (2008).

28. T. R. Ralph, M. L. Hitchman, J. P. Millington, and F. C. Walsh, Electrochim. Acta, 41(4), 591 (1996).

29. D. D. Gu, W. Meiners, K. Wissenbach, and R. Propawe, Int. Mater. Rev., 57, 133 (2012).

30. E. C. Santos, M. Shiomi, K. Osakada, and T. Laoui, Int. J. Mach. Tool Manu., 46, 1459 (2006).

31. G. E. Ryan, A. S. Pandit, and D. T. Apatsidis, Biomaterials, 29(27), 3625 (2008).

32. K. Alayavalli and D.L. Bourell, Rapid Prototyping J., 16(4), 268 (2010).

33. R. D. Johnson, Nature Chem., 4, 338 (2012).

34. M. D. Symes, P. J. Kitson, J. Yan, C. J. Richmond, G. J. T. Cooper, R. W. Bowman, T. Vilbrandt, and L. Cronin, Nature Chem., 4, 349 (2012).

35. Y. M. Chiang and B. Hellweg, Pat. US7781098 B2, (2010).

36. G. Nikiforidis, L. Berlouis, D. Hall, and D. Hodgson, J. Power Sources, 243, 691 (2013). 